\title{
Avoiding dangerous climate: results from the AVOID2 programme
}

Article

Accepted Version

Lowe, J. A., Arnell, N. W., Warren, R., Gambhir, A. J., Bernie, D. and Thompson, E. (2017) Avoiding dangerous climate: results from the AVOID2 programme. Weather, 72 (11). pp. 340-345. ISSN 0043-1656 doi:

https://doi.org/10.1002/wea.3176 Available at https://centaur.reading.ac.uk/73787/

It is advisable to refer to the publisher's version if you intend to cite from the work. See Guidance on citing.

To link to this article DOI: http://dx.doi.org/10.1002/wea.3176

Publisher: Wiley

All outputs in CentAUR are protected by Intellectual Property Rights law, including copyright law. Copyright and IPR is retained by the creators or other copyright holders. Terms and conditions for use of this material are defined in the End User Agreement.

\section{www.reading.ac.uk/centaur}

\section{CentAUR}

Central Archive at the University of Reading 
Reading's research outputs online 


\title{
Avoiding dangerous climate: results from the AVOID2 programme
}

\author{
J. A. Lowe, N. W. Arnell, R Warren, A. J. Gambhir, D. Bernie and E Thompson
}

The AVOID2 programme provided evidence for UK Government on what might constitute dangerous climate change and the feasibility of avoiding it. The programme quantified some of the benefits of moving from a world that warms by around $4-5^{\circ} \mathrm{C}$ to one limiting global warming to below or well below $2^{\circ} \mathrm{C}$. Whilst there is evidence that this transition is feasible it will require early action to reduce emissions and to develop the potential for large-scale deployment of a range of low carbon technologies.

\section{Introduction}

Article 2 of the United Nations Framework Convention on Climate Change (UNFCCC) requires governments to avoid dangerous climate change (UNFCCC, 1992). However, whilst this aim is supported by most of the world's nations its implementation in practice remains a major challenge. There is no single accepted definition of dangerous climate change and there are different views over how such a quantity should be expressed. For instance, should it be defined in terms of triggering some rapid or irreversible change in a large-scale aspect of the planetary system, such as the loss of the Greenland ice sheet or a major shift in the circulation of the Atlantic Ocean? Or should it be defined in terms of impacts on people affected by flooding, or lack of water or food availability?

The climate policy community has taken a pragmatic approach to this uncertainty and lack of agreement over what is a dangerous future by focusing on a limit to increases in global average near-surface temperatures. After the Copenhagen UN conference in 2009 this target was set at $2^{\circ} \mathrm{C}$ above pre-industrial levels. More recently the 2015 Paris Agreement defined a new and tighter long-term goal of limiting warming to well below $2^{\circ} \mathrm{C}$, and set an additional aspirational target of aiming towards $1.5^{\circ} \mathrm{C}$ (UNFCCC, 2015a). The Paris Agreement also contains a requirement to achieve net zero emissions of greenhouse gases before the end of the 21st century. In the real world such targets are inevitably a compromise between current estimates of the damage caused by future climate change and the ability for society to make the greenhouse gas emissions reductions needed to limit global average warming (and damage from climate change) below a given level.

In order to make informed decisions about targets and how to achieve them, climate policymakers need robust and reliable information. The reports of the Intergovernmental Panel on Climate Change (IPCC) provide much information, but these reports are assessments of published studies which have been undertaken for a wide variety of reasons with many different objectives. Policymakers often have very specific questions which cannot be answered by looking into the published literature. In the United Kingdom, the Government commissioned two research programmes, known as AVOID1 (see Arnell et al. (2013) and Warren et al. (2013) for summaries) and AVOID2, to provide policy-relevant information in the run-up to the annual 
conferences of the parties to the UNFCCC - culminating in the Paris conference in December 2015. AVOID results also contributed to the UN's structured expert dialogue in 2013-2015, which reviewed both scientific evidence and policy considerations of the long-term climate goal and contributed to the major revisions in climate targets agreed at the Paris climate conference (UNFCCC, 2015b).This paper provides a brief overview of the AVOID2 programme.

\section{The AVOID2 programme}

The AVOID2 programme (http://www.avoid.uk.net/) ran from 2013 to 2016, and addressed three broad questions posed by climate policymakers: What are the characteristics of 'dangerous' climate change? What greenhouse gas emissions pathways will avoid 'dangerous' climate change? What is the feasibility of such pathways?

The questions addressed by the project evolved as the policy context changed. In particular, the 2013 UNFCCC conference requested countries to make pledges outlining their proposed emissions of greenhouse gases by 2030, in preparation for a deal to be reached at the 2015 Paris conference (UNFCCC, 2013). The AVOID2 programme therefore also investigated the effects of these pledges on the likelihood of meeting climate targets, under the broad framework of the second research question.

The AVOID2 programme involved reviewing the existing literature that was most relevant to the policy questions, re-analysing data from other studies and projects, and undertaking new analyses using (mostly) existing models. Central to the programme was continued dialogue with climate policymakers within the UK government to ensure not only that the research was addressing the right policy questions but also that the results were presented appropriately. Policymakers need 'headline' results - because they are assimilating a great deal of information from multiple sources - but also need to be aware of the limitations and caveats to the research. The AVOID2 programme therefore produced not only research reports, but high-level two-page 'policy cards' and one-page 'infographics'. A number of scientific journal articles have been produced already based on the research and further are in preparation or in review.

\section{What are the characteristics of 'dangerous' climate change?}

The purpose of this question was to provide information to policymakers on the risks of potential major abrupt or irreversible changes in climate and what the impacts might be under unmitigated emissions.

\subsection{Large-scale climate system changes and "tipping points"}

Several earth system processes could amplify warming (Good et al., 2014; Good et al., 2017). As permafrost melts carbon could be released from soil adding to the amount of greenhouse gas in the atmosphere and causing further warming, and this process would be effectively irreversible over centuries or more. Recent findings continue to show that the amount and rate of release are both highly uncertain but one recent study suggested this could add up to around 
$10 \%$ to warming levels in a mitigation scenario (Burke et al., 2017). The additional warming will likely be greater in scenarios with greater emissions. Major changes to the carbon cycle in tropical regions which would release more carbon into the atmosphere are also possible. Evidence from observations has added confidence in our understanding of how tropical forests are adversely affected by drought. However, earlier projections that the Amazon rainforest would suffer major die-back as a result of climate change have been superseded by projections suggesting that loss of the Amazon rainforest is less likely to happen due to climate change alone during the $21^{\text {st }}$ century.

Several thresholds involving large-scale system change involve the cryosphere. Loss of ice from the ice sheets can raise sea levels and may impact on ocean circulation. Collapse and melting of the Antarctic West Sheet (WAIS) and Greenland Ice Sheet could result in eventual sea level rise contributions of up to around $10 \mathrm{~m}$ or more, but this would take many centuries. For comparison, the IPCC range of sea level rise under high emissions by 2100 is $0.52-0.98 \mathrm{~m}$ (IPCC, 2013). For Greenland, observations show that the proportion of loss from surface melt has increased, becoming more consistent with long term model projections. One recent estimate suggests a global-mean warming threshold for irreversible Greenland Ice Sheet loss of 0.8-3.2 ${ }^{\circ} \mathrm{C}$ (best estimate $1.6^{\circ} \mathrm{C}$ ) above pre-industrial, but the warming would need to be sustained for a very long period (Robinson et al., 2012). Additionally, there may be more than one stable configuration from this ice sheet. The bedrock topography of the WAIS lends itself to an inherently unstable ice sheet. Some degree of irreversible loss may have begun, although the eventual magnitude and rate of this irreversible loss is uncertain (Feldmann and Levermann, 2015). There are new indications that the East Antarctic Ice Sheet (EAIS) and the northeast Greenland ice stream may be more sensitive to climate change than previously expected (Good et al., 2017).

Loss of sea ice does not have a major direct effect on sea level but is an icon of a changing climate and can have significant effects on biodiversity and atmospheric circulation over Europe. Current estimates suggest that Arctic summers that are nearly ice-free are possible by the middle of the $21^{\text {st }}$ century under high emissions, although this may be delayed or even avoided with lower climate targets (IPCC, 2013).

Concern also remains that a major shift in Atlantic Ocean currents could occur with a collapse of the Atlantic meridional overturning circulation, greatly reducing the northward heat transport in the ocean. If a collapse were to occur it would have impacts such as reducing temperature, changing the spatial distribution of rainfall, and reducing plant productivity over a large fraction of the northern hemisphere (e.g. Vellinga and Wood, 2002). There is now greater awareness of the large natural variations in this ocean current on time-scale of decades or several decades but the current view remains similar to that of the last IPCC assessment, that a collapse of the circulation is unlikely during the 21st century (IPCC, 2013; Good et al., 2017).

Overall, although the potential impacts of these large-scale changes are large and there is strong evidence that the likelihood of triggering the worst changes is lower with lower levels of 
warming, the science is not yet at a point where it can say with a high degree of confidence the temperatures at which large-scale system changes might be triggered.

\subsection{Socio-economic impacts}

Policymakers are interested not only in the risk of large-scale climate changes and physical impacts but also the socio-economic impacts of climate change. These depend not only on the amount of climate change, but also on future changes in socio-economic characteristics and future adaptations to changing climate risks. There are, of course, a great many potential socioeconomic impacts of climate change, and the AVOID2 programme focused on indicators in different sectors which could readily be quantified under climate and socio-economic scenarios; it also considered some impacts on biodiversity.

Figure 1 shows the change through the $21^{\text {st }}$ century in four indicators of socio-economic impact, under high and low emissions scenarios (Arnell et al., 2016a). In each case, the impacts are calculated by first estimating the change in global mean temperature under each scenario using the MAGICC simple climate model, and then combining these temperatures with damage functions (Arnell et al., 2016b), which relate impact to change in global mean temperature. These damage functions were constructed using global-scale impacts models estimating impacts at a fine spatial resolution, run with scenarios describing changes in precipitation, temperature and other relevant climate variables derived from climate models and corresponding to different amounts of global warming.

The four indicators shown in Figure 1 represent increases in exposure to water resources stress, the numbers of people exposed to river flooding, the area of cropland with a decline in suitability for agriculture, and the numbers of people exposed to heatwaves. The impacts assume a 'middle-of-the-road' socio-economic scenario, and the range shown in Figure 1 for each indicator represents uncertainty in both the projected increase in temperature and the spatial pattern of change in rainfall and temperature. If the global average temperature increases by $5^{\circ} \mathrm{C}$, in 2100 approximately 3 billion people would be at increased risk of water scarcity, 150 million people would be exposed to river flooding each year, 7.5 million $\mathrm{km}^{2}$ of cropland (just over 50\%) would become less suitable for agriculture than it is at present, and more than 12 billion people would be exposed to heatwaves per year (meaning that many people would be exposed more than once). The figure also shows that impacts would be reduced substantially under a lower-emissions pathway that met a $2^{\circ} \mathrm{C}$ target, with different proportional effects for the different indicators. This is because the shape of the relationship between level of warming and impact varies between sectors. Future adaptations to climate change are not included, so the figure represents exposure to risk rather than predicted actual impact.

For a given emissions scenario, there is clearly a wide range of uncertainty in the estimated impacts. This is due to uncertainty in the projected regional changes in climate, particularly 
precipitation. The figure also hides considerable variability in impact between regions (Arnell et al., 2016a).

\section{What greenhouse gas emissions pathways will avoid 'dangerous' climate change?}

This part of the programme examined the emissions pathways that would achieve specific climate targets, and also at the effects of the pledges of emission reductions made by countries prior to the Paris Agreement.

\subsection{What pathways meet specific climate targets?}

The first AVOID approach to investigating the feasibility of limiting warming to below $2^{\circ} \mathrm{C}$ or even $1.5^{\circ} \mathrm{C}$ used the IPCC 5th assessment database of integrated assessment modelling scenarios (IPCC, 2014; Bernie \& Lowe, 2014). This is a database of around 1000 different potential scenarios for future emissions and, when there is enough detail to simulate the climate, the future global temperature change, made using a wide variety of integrated assessment models and socio-economic assumptions. The scenarios were defined to answer particular questions, so do not necessarily span the full range of uncertainty, but nevertheless provide an indication of how different emissions pathways could translate into changes in temperature.

Only around 80 scenarios in the database with emissions that peak at or after 2015 (the best that can be expected in reality) result in a warming of no more than $2^{\circ} \mathrm{C}$. Half of these reach below $1.75^{\circ} \mathrm{C}$ by year 2100 , but none fall below $1.5^{\circ} \mathrm{C}$. Many of the scenarios that produce temperature increases below $2^{\circ} \mathrm{C}$ in 2100 actually include a temperature 'overshoot' with higher temperatures earlier in the century: this overshoot can be up to 60 years long, and most overshoots are less than $0.2^{\circ} \mathrm{C}$. In most of the sub- $2^{\circ} \mathrm{C}$ scenarios total primary energy use is higher in 2100 than at the present day, but in all there are major reductions in fossil fuel use, usually the rapid deployment of carbon capture and storage (CCS) technologies, and rapid deployment of renewable power generation. The split between different renewable sources varies between scenarios, and whilst some include nuclear power others can achieve the $2^{\circ} \mathrm{C}$ target without it.

Almost all of the scenarios include technologies to artificially remove greenhouse gases ('negative emission technologies'), of which the most widely used is BECCS (bioenergy with carbon capture and storage). Here biomass is used for power generation with the carbon that is emitted captured and put into long-term storage. However, there are biophysical constraints on the amount of BECCS that is feasible (Wiltshire \& Davies-Barnard, 2015). For instance, converting forest land to annual bioenergy crops changes the albedo of the land surface and the transfer of both heat and moisture between land and the atmosphere. These effects combine to alter the effectiveness of biofuels in regulating warming and can lead to an increase or decrease in temperature, depending on location (Betts, 2000). For conversion from forest to biofuels our modelling suggested an additional net global cooling term may result, whereas conversion of abandoned land to biofuels has less potential to make a contribution. The conversion of forest 
also releases extra carbon into the atmosphere: our results show that planting biomass crops for BECCS in the wrong place could therefore increase $21^{\text {st }}$ century global temperatures. Taking these biophysical, earth system and feasibility effects together, the evidence suggests that the amount of BECCS that is biophysically-feasible may be less than the amount assumed in many of the published emissions scenarios which achieve low temperature targets. Further, the land which is biophysically-feasible for BECCS may be required for food production or have high conservation value.

The scenarios that reach year 2100 with a global mean warming between 1.75 and $2^{\circ} \mathrm{C}$ typically peak emissions between 2020 and 2030, have net negative emissions from between 2060 and 2080 and a mean 2030 to 2050 reduction in annual $\mathrm{CO}_{2}$ emissions of around $\sim 25 \mathrm{GtCO}_{2}$ (Figure 2). The scenarios that reach below $1.75 \mathrm{C}$ by 2100 typically have emissions peaks and a start of negative emissions weighted earlier than the 1.75 to $2 \mathrm{C}$ scenarios. This analysis is consistent with the recent review by van Vuuren et al. (2016). A new generation of scenarios is in production by the international community, which include investigating the emissions below the existing set and giving a higher chance of limiting warming to below $2^{\circ} \mathrm{C}$ (O'Neill et al., 2016).

\subsection{What are the effects of the emission reduction pledges made before the Paris Agreement on temperatures future warming levels?}

Before and following the Paris climate conference in 2015 many nations pledged emission reductions, typically out to 2030. These Nationally Declared Contributions (NDCs) are designed to encourage early action by countries towards achieving the long-term climate goal of limiting warming. A key question then becomes whether the INDCs are compatible with the long-term climate targets: are the pledges sufficient?

Our estimates in early 2015 - when many, but not all, pledges were submitted and interpreted found that if the pledges were added together they gave a central estimate of the emission level of around $54 \mathrm{GtCO}_{2} \mathrm{e}^{1}$ in 2030 , with an uncertainty range that depends on how the pledges are interpreted and the fact that some pledges are conditional on other conditions being met (the Paris Agreement subsequently puts the central estimate at $\left.55 \mathrm{GtCO}_{2} \mathrm{e}\right)$. The AVOID2 programme first looked at the potential effects of these pledges using the scenarios in the IPCC data base, correlating emissions in 2030 with the warming by 2100 (Figure 3). There is a correlation between eventual warming and 2030 emissions level, but with emissions in 2030 up to around $55 \mathrm{GtCO}_{2} \mathrm{e}$ the rise in temperature covers a wide range and can be between 1.5 and $3.5^{\circ} \mathrm{C}$. Additionally, there are emission pathways with levels above 55GtCO2e in 2030 that still limit warming to well below $2^{\circ} \mathrm{C}$, and some pathways with emissions well below 55GtCO2e in 2030 that eventually exceed $2^{\circ} \mathrm{C}$. While the emission reductions to 2030 do encourage progress towards a low-carbon world, on their own they are not sufficient to limit warming to well below $2^{\circ} \mathrm{C}$. This is because the total carbon budget is approximately linearly proportional to warming

\footnotetext{
1 i.e. including not just carbon dioxide, but also the effects of other greenhouse gases as equivalent carbon emissions, estimated using global warming potentials.
} 
level (Allen et al., 2009), and contributions to the remaining budget can occur after 2030. Other studies looking at the Paris pledges make similar conclusions (e.g http://climateactiontracker.org/global.html).

A further strand of research in AVOID2 research provided a further way to look at pathways leading to particular levels of future warming. This approach produced new emission pathways using the TIAM-Grantham integrated assessment model (Gambhir et al., 2017a) to estimate future carbon emissions, given middle-of-the-road socio-economic assumptions. This is described in the next section.

\section{What is the feasibility of pathways which meet climate targets?}

There are several factors that determine whether a particular temperature target is feasible. One aspect relates to the characteristics of the physical climate system. For a given pathway of emissions of greenhouse gases the pathway of warming depends on metrics such as the transient climate response, equilibrium climate sensitivity and the climate-carbon cycle feedback, all of which are still highly uncertain. This means that for a given scenario of future emissions it is not possible to identify a unique warming level but rather a probability of limiting warming to below a particular value. Current conventions focus on the median warming level (giving at least $50 \%$ chance of limiting warming below a target), or the warming for which there is a likely ( $>66 \%$ ) chance of remaining below a given level. The emissions pathways that achieve low temperature targets assume the implementation of substantial amounts of BECCS, taking $\mathrm{CO}_{2}$ from the atmosphere, which brings in another aspect of physical feasibility.

A further aspect of the feasibility of limiting warming to temperature targets of below $2^{\circ} \mathrm{C}$ is whether society can devise technically and economically feasible means to satisfy the energy needs of a changing population whilst reducing emissions. For a warming level of less than $2^{\circ} \mathrm{C}$, achieved with a $50 \%$ likelihood, the feasibility question typically means 'will society be able to deploy low-carbon technologies fast enough and cheaply enough during the 21st century'? This aspect of feasibility can be examined with the TIAM-Grantham energy systems model, which simulates energy use and emissions by region and sector, and can be constrained by imposing limits on the total amount of carbon which can be emitted. Emissions of other greenhouse gases were produced using other linked energy models (Gambhir et al., 2017b). These emissions were then used as input to a version of the MAGICC simple upwelling diffusion energy balance climate model (e.g. Wigley and Raper, 2001) to estimate the global warming response and account for the physical climate system constraints on feasibility.

Our analysis with TIAM-Grantham (Gambhir et al., 2017a; Napp et al., 2017) shows that the $2^{\circ} \mathrm{C}$ is technically feasible to achieve, but the later the reductions in emissions begin and the later key technologies are deployed, the greater the costs (Figure 4). Achieving a $2^{\circ} \mathrm{C}$ target implies much higher rates of decarbonisation than seen historically (Figure 5). Achieving the energy transitions that we simulated were necessary to meet the $2^{\circ} \mathrm{C}$ target requires the uptake of a 
range of low-carbon technologies at rates of up to $20 \%$ per year. This is comparable to the fastest rates of sustained energy technology deployment seen in the past. For instance, France achieved a growth rate of around 19\% per year for nuclear power between 1977 and 1997, Denmark achieved a 20\% growth in wind power between 1997 and 2008, and global installed solar photovoltaic capacity grew from by 50\% per year from 2009 to 2014 (Napp et al., 2017). However, deploying multiple technologies at very high growth rates over sustained periods is likely to require not only reductions in the cost of renewable energy, but also effective global governance to support innovation, supply chains, skills and finance.

To examine the feasibility of the Paris pledges, we also ran the TIAM-Grantham system with the total emissions of greenhouse gases constrained to be $55 \mathrm{GtCO}_{2} \mathrm{e}$ in 2030 , and simulated how energy systems could plausibly change over the $21^{\text {st }}$ century keeping within a total carbon budget that yielded a $50 \%$ chance of keeping temperatures below $2^{\circ} \mathrm{C}$. A number of emission scenarios that were compatible with limiting warming to around $2^{\circ} \mathrm{C}$ above pre-industrial levels were produced. These new 2030 scenarios have very rapid emission reductions after 2030, with some technologies, such as use of coal, being phased out very rapidly, whilst renewable technologies and carbon capture and storage is deployed rapidly. This is consistent with our earlier assessment of existing scenarios from the IPCC assessment. However, with TIAMGrantham we were able to go further and test how limiting the deployment rates of some technologies, based on past deployment rates, could push a "well below $2^{\circ} \mathrm{C}$ " warming limit towards significantly higher costs or even out of reach. This implies the need to increase incentives and remove barriers to deployment of low-carbon technologies as soon as possible.

\section{Discussion and Conclusions}

The AVOID2 programme was designed to provide policy-relevant advice on 'dangerous' climate change to government climate policy-makers. It combined literature reviews, analysis of existing results and new assessments, typically with existing models. The programme evolved as the policy questions evolved - particularly in the run-up to the 2015 Paris conference - and much effort was devoted to presenting results in a manner directly relevant to policy makers who have to assimilate information from many different sources.

The research presented evidence to policy-makers on the characteristics of 'dangerous' climate change, identifying the major potential risks to the climate system as a whole, assessing the likelihood of passing key 'tipping point' thresholds, and describing socio-economic impacts that could be anticipated if emissions were not reduced. It was found that in order to achieve low temperature targets, such as limiting the increase in temperature to $2^{\circ} \mathrm{C}$, global emissions would ideally peak at or before 2020 to 2030 . It could be technically feasible to meet a $2^{\circ} \mathrm{C}$ target if countries met their pledges under the Paris Agreement, but this would require significant reductions in emissions in future years. However, there are biophysical, technical, economic and socio-political constraints on potential changes in future emissions - for example, for the implementation of BECCS. 
The research also highlighted a key issue with many existing scenarios of the future from integrated assessment models, which is the need to challenge with more rigour the assumptions about future technology costs and deployment rates, as we did in AVOID2. This will involve testing the assumptions more in terms of past changes and questioning further the engineering aspects of the technologies that might be needed. Additionally, there is also a need to better account for political and behavioural aspects of feasibility. These provide limits on whether the model worlds described in scenarios from integrated assessment models become feasible in the real world.

Whilst the AVOID2 programme provided many answers to policy-maker questions, it also identified major gaps in our understanding of how the climate system is likely to respond not only to future emissions but also to policy interventions to reduce those emissions. For example, important bio-physical processes and feedbacks - such as the thawing of permafrost - are currently not well-represented in models and can have a big effect on future changes in climate. The programme also challenged the project scientists to present complex information, characterised by high uncertainty, to policy audiences in ways that succinctly presented the headline messages whilst preserving the caveats.

Finally, whilst our focus was on warming limits of below or well below $2 \mathrm{C}$ there is an increased focus on looking even lower at $1.5 \mathrm{C}$. AVOID2 provides research approaches that can be deployed further for these lower warming limits.

\section{Acknowledgements}

This research uses results from the AVOID2 programme (DECC and Defra) under contract number 1104872 (www.avoid.uk.net).

\section{References}

Allen, M.R. et al. (2009) Warming caused by cumulative carbon emissions towards the trillionth tonne. Nature 458, 1163-1166

Arnell, N.W., Lowe, J.A., Brown, S., Gosling, S.N., Gottschalk, P., Hinkel, J., Lloyd-Hughes, B., Nicholls, R.J., Osborn, T.J., Osborne, T.M., Rose, G.A., Smith, P. \& Warren, R.F. (2013) A global assessment of the effects of climate policy on the impacts of climate change. Nature Climate Change 3, 512-519.

Arnell, N.W. et al. (2016a) Global and regional impacts of climate change under Representative Concentration Pathways (RCPs). AVOID 2 WPB2b (http://www.avoid.uk.net/)

Arnell, N.W. et al. (2016b) Global-scale climate impact functions: the relationship between climate forcing and impact. Climatic Change 134, 475-487

Bernie, D. \& Lowe, J.A. (2014) Future temperature responses based on IPCC and other existing emissions scenarios. AVOID 2 WPA.1 Report 1 (http://www.avoid.uk.net/)

Betts, R. (2000) Offset of the potential carbon sink from boreal forestation by decreases in surface albedo. Nature 408, 187-190. 
Burke EJ, Ekici A, Huang Y, Chadburn SE, Huntingford C, Ciais P, Friedlingstein P, Peng SS, Krinner G. Quantifying uncertainties of permafrost carbon-climate feedbacks. Biogeosci. 14, 3051-3066. (doi:10.5194/bg-14-3051-2017)

Feldmann, J. and A. Levermann (2015). Collapse of the West Antarctic Ice Sheet after local destabilization of the Amundsen Basin. Proceedings of the National Academy of Sciences of the United States of America 112(46): 14191-14196. doi:10.1073/pnas.1512482112.

Gambhir, A. et al. (2017a) Assessing the feasibility of global long-term mitigation scenarios. Energies 10, 89; doi:10.3390/en10010089

Gambhir, A. et al. (2017b) The contribution of non-CO2 greenhouse gas mitigation to achieving long-term temperature goals. Energies 10, 602; doi:10.3390/en10050602

Good, P. et al. (2014) An updated view of tipping points and the relevance for long-term climate goals. AVOID 2 WPA.5 Report 1 (http://www.avoid.uk.net/)

Good P et al. (2017). Recent progress in understanding climate thresholds: ice sheets, the Atlantic meridional overturning circulation, tropical forests and responses to ocean acidification. Under review at Progress in Physical Geography.

IIASA (International Institute for Applied Systems Analysis) (2015) AR5 Scenario Database http://tntcat.iiasa.ac.at/AR5DB (2015)

IPCC (2013) Summary for Policymakers, in Climate Change 2013, The Physical Science Basis. Stocker, T. et al. (eds) (Cambridge Univ. Press).

IPCC, 2013 Climate Change 2013: The Physical Science Basis. Contribution of Working Group I to the Fifth Assessment Report of the Intergovernmental Panel on Climate Change [Stocker, T.F., D. Qin, G.-K. Plattner, M. Tignor, S.K. Allen, J. Boschung, A. Nauels, Y. Xia, V. Bex and P.M. Midgley (eds.)]. Cambridge University Press, Cambridge, United Kingdom and New York, NY, USA, 1535 pp

IPCC, 2014b Climate Change 2014: Mitigation of Climate Change. Contribution of Working Group III to the Fifth Assessment Report of the Intergovernmental Panel on Climate Change [Edenhofer, O., R. Pichs-Madruga, Y. Sokona, E. Farahani, S. Kadner, K. Seyboth, A. Adler, I. Baum, S. Brunner, P. Eickemeier, et al. (eds.)]. Cambridge University Press, Cambridge, United Kingdom and New York, NY, USA.

Napp, T. et al (2017) Exploring the feasibility of low-carbon scenarios using historical energy transitions analysis. Energies 10, 116; doi:10.3390/en10010116

O'Neill, B. C., Tebaldi, C., van Vuuren, D. P., Eyring, V., Friedlingstein, P., Hurtt, G., Knutti, R., Kriegler, E., Lamarque, J.-F., Lowe, J., Meehl, G. A., Moss, R., Riahi, K., and Sanderson, B. M (2016). The Scenario Model Intercomparison Project (ScenarioMIP) for CMIP6, Geosci. Model Dev., 9, 3461-3482, doi:10.5194/gmd-9-3461-2016.

Robinson A., Calov R. and Ganopolski A (2012). Multistability and critical thresholds of the Greenland ice sheet. Nature Climate Change. 2, doi:10.1038/nclimate1449

UNFCCC (1992) United Nations Framework Convention on Climate Change FCCC/Informal/84 UNFCCC (2013) Further Advancing the Durban Platform. FCCC/CP/2013/10/Add.1

UNFCCC (2015a) Adoption of the Paris Agreement FCCC/CP/2015/L.9/Rev.1 United Nations Framework Convention on Climate Change 
UNFCCC (2015b) Report on the structured expert dialogue on the 2013-2015 review. FCCC/SB/2015/INF.1 (http://unfccc.int/science/workstreams/the_20132015_review/items/7521.php)

van Vuuren DP et al. (2016). Carbon budgets and energy transition pathways. Environmental Research Letters, Volume 11, Number 7.

Vellinga, M. \& Wood, R.A. (2002) Global climatic impacts of a collapse of the Atlantic Thermohaline Circulation Climatic Change 54: 251-267 doi:10.1023/A:1016168827653.

Warren, R., Lowe, J.A., Arnell, N.W., Hope, C., Berry, P., Brown, S., Gambhir, A., Gosling, S.N., Nicholls, R.J., O'Hanley, J., Osborn, T.J., Osborne, T., Price, J., Raper, S.C.B., Rose, G. \& Vanderwal, J. (2013). The AVOID programme's new simulations of the global benefits of stringent climate change mitigation. Climatic Change 120: 55-70.

Wigley TM, Raper SCB. 2001 Interpretation of high projections for global-mean warming. Science 293, 451-4. (doi:10.1126/science.1061604) 

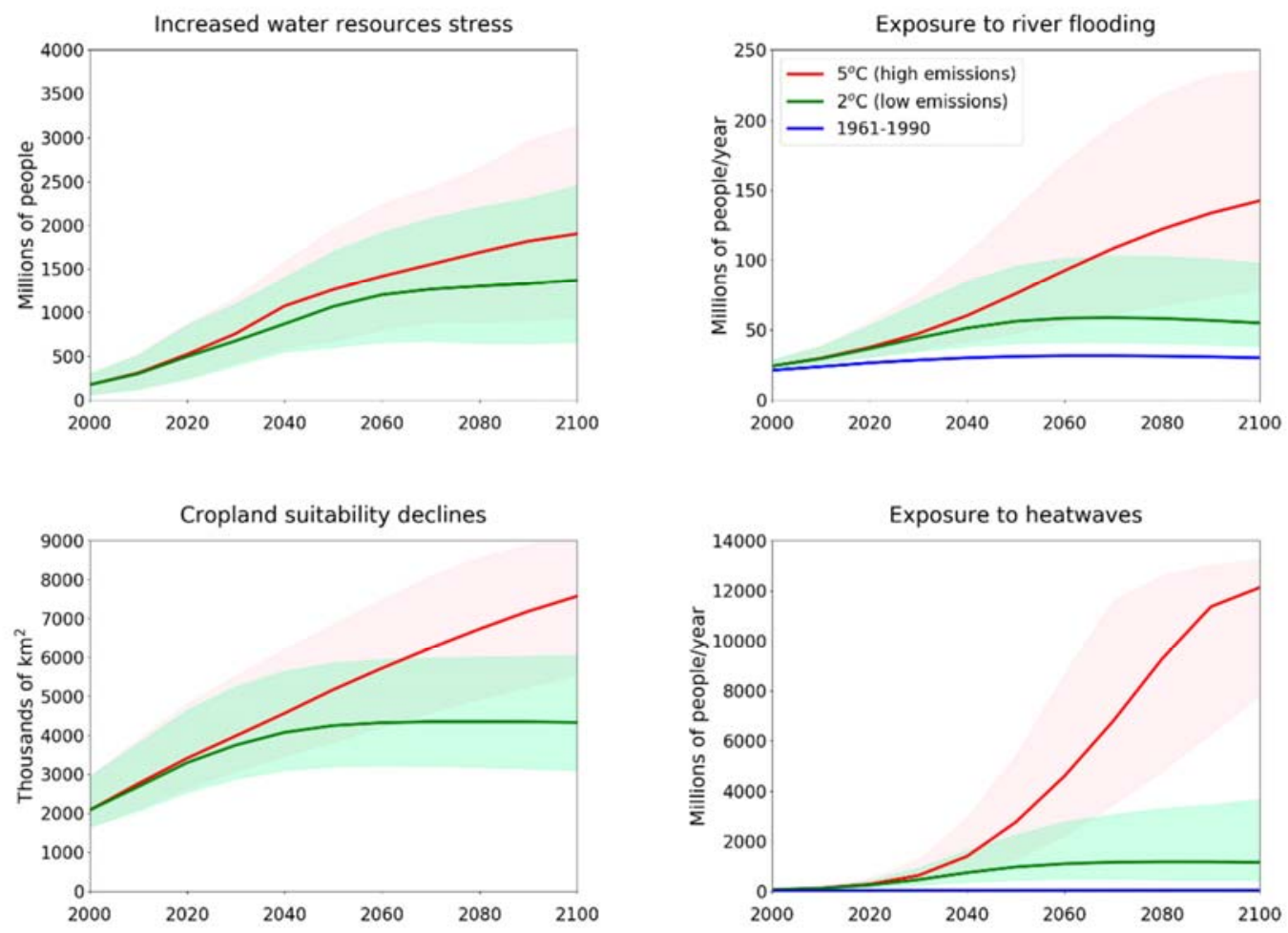

Figure 1: Global impacts for four indicators under two emissions pathways. The high emissions pathway is RCP8.5 and the lowest is RCP2.6. The solid line shows the median estimate of impact and the shaded area shows the $10^{\text {th }}$ to $90^{\text {th }}$ percentile range. The plots for the flooding and heatwave indicators also show the impacts that would arise if climate remained at the 19611990 level. 

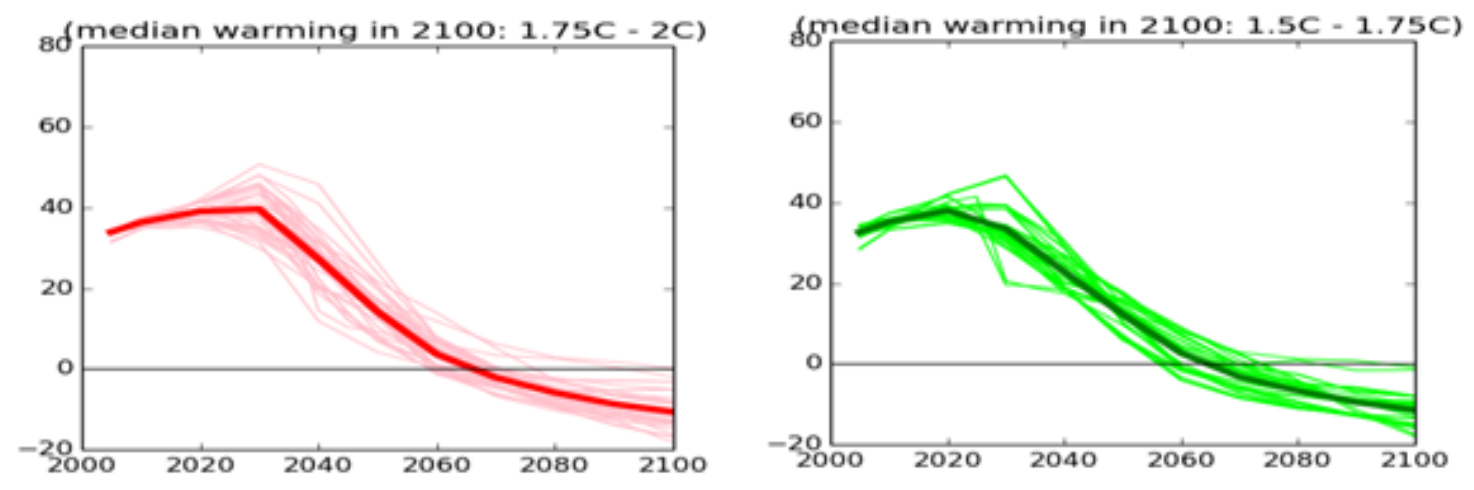

Figure 2: Emissions of $\mathrm{CO}_{2}\left(\mathrm{GtCO}_{2}\right)$ for the subset of scenarios that reach 2100 with a warming in the range 1.75 to $2 \mathrm{C}$ (left) and 1.5 to $1.75 \mathrm{C}$ (right).

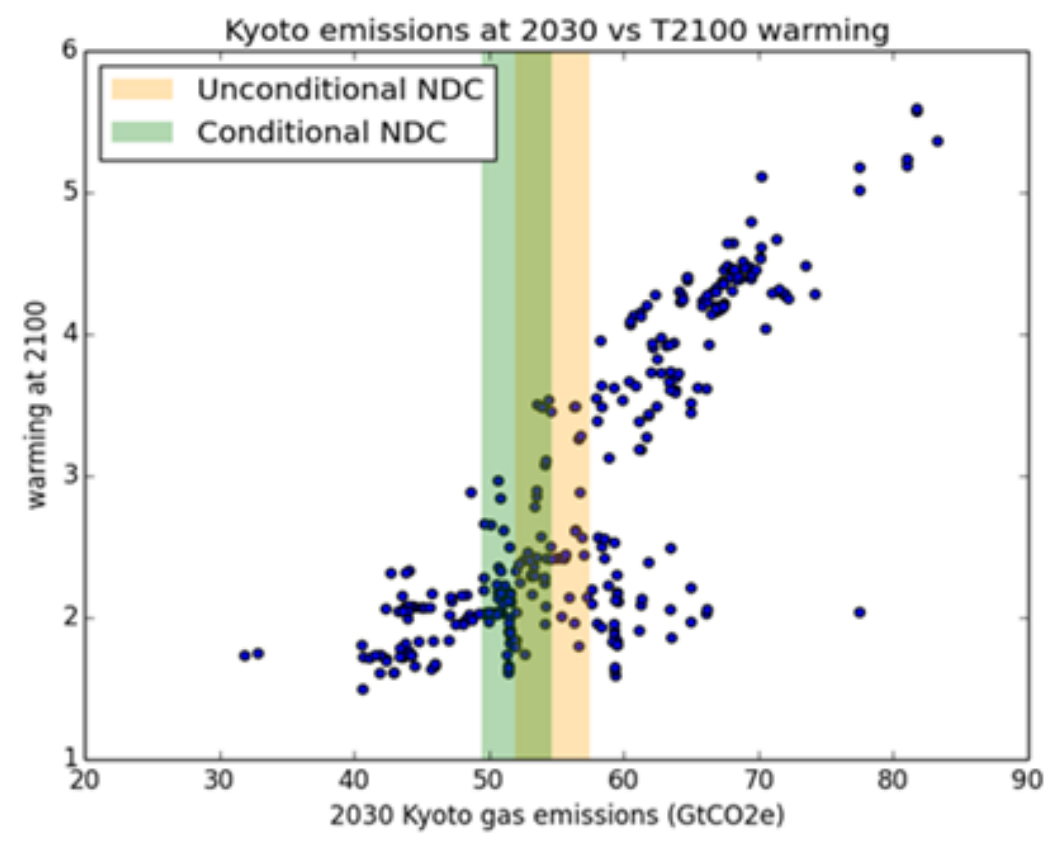

Figure 3: Median warming in 2100 plotted against 2030 emissions: scenarios from the IPCC WG3 data base. The vertical bars show the range of the NDC pledges. 


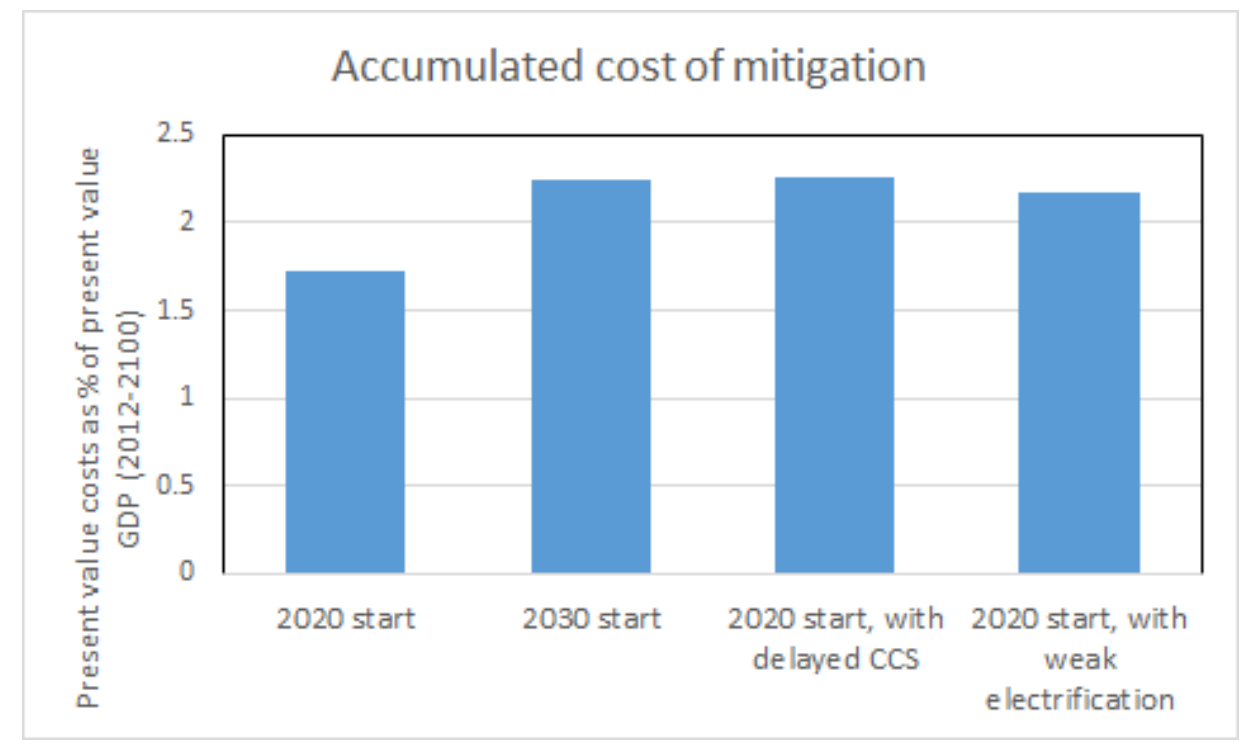

Figure 4: Illustrative accumulated $2012-2100$ costs of mitigation to achieve a $2^{\circ} \mathrm{C}$ target, as share of global GDP, with different assumptions about the rate of deployment of new technologies. The costs were estimated using the TIAM-Grantham model, assuming a 5\% discount rate.

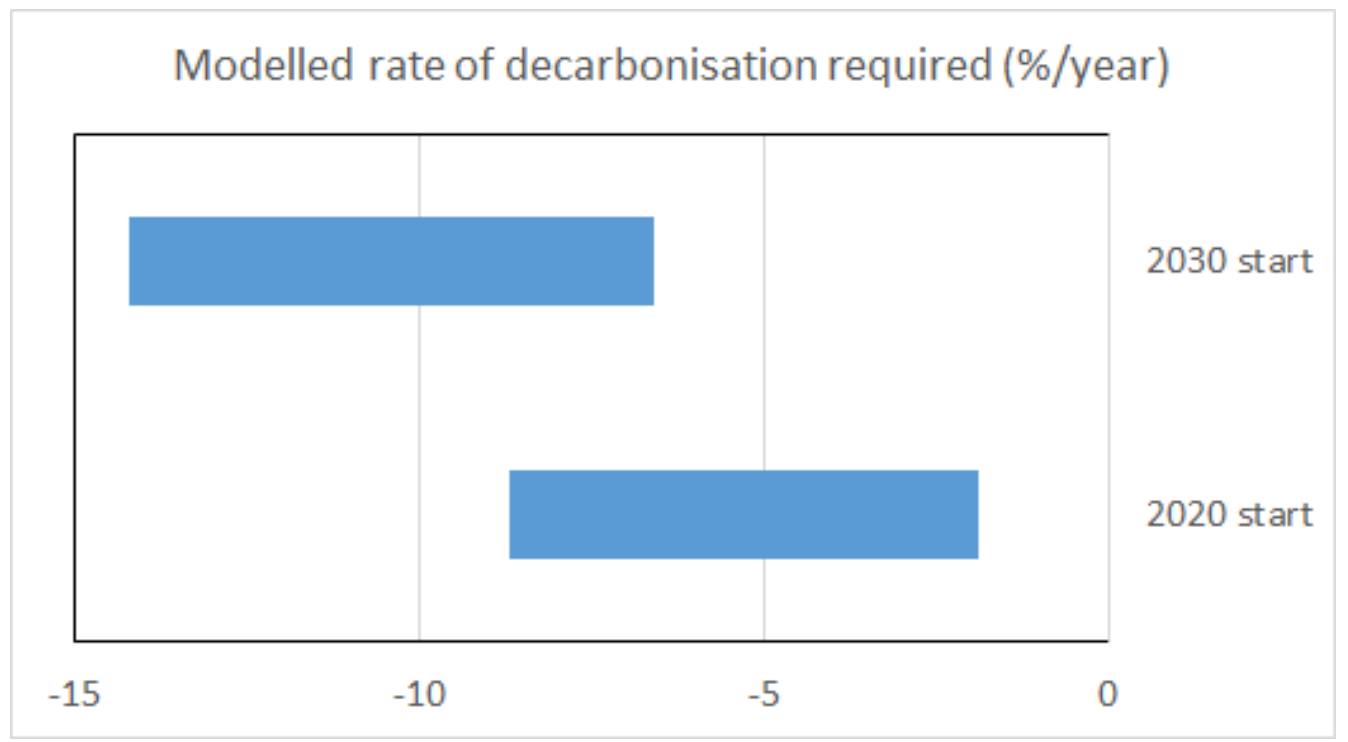

Figure 5: Estimated average annual rate of change of global $\mathrm{CO}_{2}$ emissions in the first decade after the start of global coordinated mitigation action to remain below $2^{\circ} \mathrm{C}$ in 2100 begins; the range is across three estimates. 
